\title{
Governança Global da Internet: Um mapa da Economia Política Internacional em torno dos identificadores alfanuméricos da rede ${ }^{1}$
}

\author{
Global Internet Governance: \\ A map of the International Political Economy \\ around the network's alphanumeric identifiers
}

DOI: $10.21530 /$ ci.v13n1.2018.748

Diego Rafael Canabarro²
Alexandre Arns Gonzales ${ }^{3}$

\section{Resumo}

Este artigo objetiva analisar a formação do regime internacional privado em torno da "raiz" do Sistema de Nomes de Domínio (DNS) da Internet. O problema que orienta este texto é: qual a relação da constituição desse regime e a emergência de novos mecanismos de governança global? Este artigo objetiva detalhar de forma sintética tal evolução, pontuando a forma pela qual os diferentes arranjos de governança do DNS relacionam-se com a economia política internacional em uma perspectiva mais ampla. Para isso, o texto divide-se em três seções. A primeira seção apresenta e explica o DNS, em sua dimensão técnica e política. A segunda seção empreende uma retrospectiva da governança da Internet até o presente

1 As opiniões expressas no texto não representam e não se confundem com posicionamentos das instituições às quais os autores estão vinculados. Uma versão preliminar do trabalho foi apresentada no 60 Encontro da Associação Brasileira de Relações Internacionais (ABRI), que ocorreu entre os dias 25 e 28 de julho de 2017 em Belo Horizonte (MG). Os autores agradecem a todas as pessoas que revisaram e contribuíram para a consolidação da versão atual do texto desde a primeira divulgação para revisão de pares.

2 Doutor em Ciência Política pela UFRGS. Pesquisador Centro de Estudos Internacionais sobre Governo (CEGOV) na mesma universidade e do Instituto Nacional de Ciência e Tecnologia em Democracia Digital (INCT-DD). Atualmente, trabalha no NIC.br, na equipe de assessoria do Comitê Gestor da Internet no Brasil/CGI.br. Sua atuação na confecção desse trabalho não contou com qualquer financiamento. Entretanto, sua pesquisa doutoral de 2010 a 2014 (da qual deriva o conhecimento pertinente ao tema) contou com financiamento da Coordenação de Aperfeiçoamento de Pessoal de Nível Superior (Capes).

3 Doutorando em Ciência Política pela UnB, Bolsista/CAPES. É Mestre em Ciência Política pela UFRGS, Bacharel em Relações Internacionais pela UNIPAMPA. Sua atuação na confecção desse trabalho foi possível em virtude do financiamento da Capes.

Artigo submetido em 31/01/2018 e aprovado em 21/03/2018. 
momento. Sintetiza-se essa retrospectiva pela lente interpretativa de uma análise sistêmica de longa duração. Na terceira seção, explica-se de que forma os desdobramentos da transição da autoridade sobre o DNS podem relacionar-se com a conformação de transformações na governança global e aponta-se para os caminhos pretendidos para o aprofundamento do tema. Ao fim, o trabalho procura apontar os aspectos práticos e teóricos que merecem ser considerados na agenda de ensino e pesquisa do campo.

Palavras-chave: Capitalismo; Internet; Governança; Relações Internacionais.

\begin{abstract}
This paper aims to analyze the formation of the private international regime around the "root" of the Internet's Domain Name System (DNS). The problem that guides this text is: what is the relation between the constitution of that regime and the emergence of new mechanisms of global governance? This paper aims to summarize this evolution, pointing out the way in which the different DNS governance arrangements relate to the international political economy in a broader perspective. For this, the text is divided into three sections. The first section presents and explains DNS in its technical and political dimension. The second section looks at a retrospective of Internet governance to date. This retrospective is synthesized based on the interpretive lens of a long-term systemic analysis. In the third section, it is explained how the unfolding of the transition from the authority to the DNS can be related to the transformation of global governance and points to the paths intended to deepen the theme. At the end, the paper seeks to point out the practical and theoretical aspects that should be considered in the teaching and research agenda of the field.
\end{abstract}

Keywords: Capitalism; Internet; Governance; International Relations.

\title{
Introdução
}

O Sistema de Nomes Domínios da Internet (DNS) é um dos elementos estruturais da atual arquitetura da Internet. Historicamente, da criação da Internet até 2016, o governo estadunidense supervisionou diretamente as entidades privadas encarregadas de gerenciar o DNS. A partir de 2016, em um processo de “privatização do DNS”, o sistema passou a ser governado inteiramente por um arcabouço institucional não governamental centrado eminentemente em atores vinculados à jurisdição dos Estados Unidos. Nesse sentido, o DNS possui relevância para as relações internacionais, pois envolve disputas sociopolíticas e econômicas 
entre atores estatais e não estatais que ocorrem fora dos marcos institucionais que são próprios das relações internacionais modernas.

O fim da supervisão do Departamento de Comércio dos EUA sobre os recursos de endereços, nomes e números da Internet, exercida por quase duas décadas em virtude do vínculo contratual da Corporação da Internet para Atribuição de Nomes e Números (ICANN) com a Agência Nacional de Telecomunicações e Informação (NTIA) dos Estados Unidos, sinaliza um relevante marco no processo histórico em torno da agenda de governança da Internet nas relações internacionais. A não renovação do contrato e aprovação dos planos de trabalho para internacionalização da ICANN, no dia 30 de setembro de 2016, conferem um aparente desfecho ao processo aberto com a relação da primeira edição da Cúpula Mundial pela Sociedade da Informação (CMSI), em 2003.

Ademais, esse desfecho relaciona-se conceitual e praticamente com o processo de transição de um ciclo sistêmico de acumulação do capitalismo, o "fim do longo século XX” (SILVER; ARRIGHI, 2012), conformando uma transformação nos mecanismos de governança global que abre margem de oportunidade de ascensão de uma nova hegemonia. Ainda, a desvinculação contratual da ICANN com o aparelho estatal estadunidense carrega dentro de si o éthos de contestação ao sistema multilateral e intergovernamental constituído no século XX, no imediato pós-guerra.

Para contribuir com a adequada interpretação desses acontecimentos, este artigo aborda a relevância e discorre sobre consequências da formação do regime internacional centrado em atores não estatais em torno do DNS. Para isso, detalha de forma sintética as disputas sociopolíticas e econômicas entre atores estatais e não estatais, pontuando a forma pela qual os diferentes arranjos de governança do DNS relacionam-se com a economia política internacional em uma perspectiva histórica mais ampla.

A metodologia que guiou o desenvolvimento de tal análise envolveu o rastreamento histórico de processos políticos, análise documental e revisão da literatura relativa à análise de sistema-mundo e à evolução da arquitetura institucional da governança global da Internet. Os autores realizaram imersões no campo estudado que permitiram acesso aos documentos e pronunciamentos apresentados neste trabalho. O universo de eventos acompanhados presencialmente englobou: doze (12) reuniões da ICANN, realizadas entre 2014 e 2017; o Encontro NETmundial realizado em 2014, em São Paulo; e, de 2012 até o presente momento, tem-se acompanhado listas de correios eletrônicos de grupos de trabalho e formulações de políticas da comunidade da própria ICANN. A revisão de literatura, 
por sua vez, debruçou-se sobre a noção de "ciclos sistêmicos de acumulação", trabalhados por Giovanni Arrighi, e a noção de análise de "longa duração" do capitalismo, estruturada a partir de Fernand Braudel. O trabalho, nesses termos, toma como ponto de partida a constituição da ICANN em 1998, procurando relacionar tais eventos a elementos de constituição de novos mecanismos de governança global do sistema de Estados nacionais.

O texto divide-se em três grandes seções. A primeira seção explicará em que consiste o DNS, revisando a bibliografia e a documentação técnica que tratam do sistema e, também, documentação da própria ICANN (que indica os desenvolvimentos técnicos e as questões políticas que os circundam). Na segunda seção, empreende-se uma retrospectiva da governança da Internet até o presente momento, associando-a à própria história do capitalismo e, dele, com a história geral do mundo (BRAUDEL, 1987). Na terceira seção, então, aponta-se de que forma os desdobramentos da transição da autoridade sobre o DNS podem relacionar-se com transformações na governança global em um sentido mais amplo. Ao fim, o trabalho procura apontar os aspectos práticos e teóricos que merecem ser considerados na agenda de ensino e pesquisa do campo.

\section{O sistema de nomes domínios da internet e as relações internacionais}

O Sistema de Nomes Domínios (DNS, em inglês) foi desenvolvido para substituir a antiga tabela de endereços numéricos, armazenada em um arquivo (hosts.txt) que mapeava o conjunto de dispositivos computacionais conectados à rede da Agência de Projeto de Pesquisa Avançados (ARPANET, acrônimo em inglês), desde a década de 1970. O objetivo de vincular os endereços numéricos a nomes consistia em facilitar o uso da rede, especialmente pelo crescimento de dispositivos conectados a ela (KLENSIN, 2003,). Em vez de precisar saber que o endereço para determinado sítio é 196.164.1.1, bastaria o usuário indicar o endereço "exemplo.com.br". A tabela armazenada pelo arquivo hosts.txt continha essa lista de correspondência para toda a rede. Quanto mais crescia a Internet, mais complexo e pesado ficava o arquivo, gerando um problema em escala. A solução encontrada para facilitar o acesso e a difusão do arquivo por meio da própria rede foi a estruturação de uma base de dados permanentemente disponível para consulta em um conjunto de nodos centrais. 
O DNS serve como um sistema de indexação hierárquico, cujo topo (o conjunto de nodos centrais do sistema) é a chamada "raiz". O sistema subdivide-se em inúmeros domínios no topo (as palavras mais à direita de um determinado endereço da Internet), como, por exemplo, o.com, o.br e o.net. Cada um desses domínios é administrado por pessoas e entidades de diferentes naturezas. Os responsáveis por um determinado domínio (representado por um "nome de domínio") podem criar subdomínios (ou nomes secundários, terciários e, assim, sucessivamente), sempre anotados à esquerda do nome inserido no nível anterior ${ }^{4}$. Tomemos como exemplo o .org.br, empregado pelo domínio da ABRI (abri.org.br). O nome .org encontra-se listado na base de dados referente ao .br e os nomes inseridos sob o .org.br encontram-se na base de dados correspondente, aquela referente ao .org.br.

Segundo a lógica de funcionamento da Internet, não cabe à raiz armazenar as informações completas de endereçamento que são próprias de cada um desses domínios. Basta que ela divulgue a informação que leve à base de dados referente a um domínio de topo. Nessa base de dados do domínio de topo, constarão os endereços das bases de dados de domínios de hierarquia inferior (que podem indicar endereços de sítios web, de servidores de e-mail, de outras redes da Internet etc.) e assim por diante. Esse sistema procura simplificar o processo de tradução de nomes em números, fazendo com que um servidor DNS de nível superior tenha apenas que armazenar as direções dos servidores DNS de nível inferior que, quando consultados, por sua vez terão o trabalho de completar um determinado encaminhamento na Internet.

Figura 1. Organograma da hierarquia do DNS

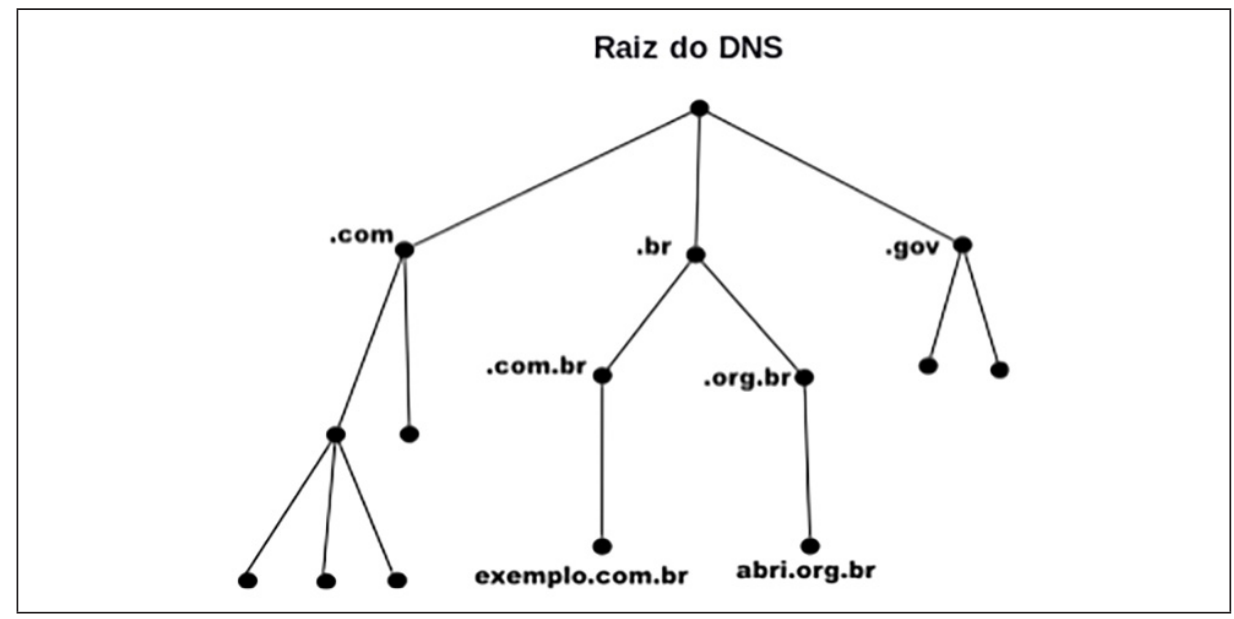

Fonte: elaborado pelos autores.

4 Essa descrição dos diferentes níveis de nomes que estruturam o DNS foi retirada da RFC 1591/1994 (Domain Name System Structure and Delegation). A descrição encontra-se em IETF (1994). 
A raiz do DNS encontra-se replicada em uma base de dados distribuída em treze computadores específicos espalhados pelo mundo, que são centrais para a organização da relação dos endereços numéricos com seus respectivos domínios. Esses treze computadores são os denominados “servidores-raiz”. Dez deles estão nos EUA, um na Suécia, um na Holanda e outro no Japão, mas a base de dados que eles armazenam (a "raiz”) está replicada em outros servidores pelo mundo. Dentre os treze, há um que é conhecido como o “servidor-autoridade”, responsável por distribuir o arquivo com o tabelamento de endereços correspondentes aos domínios de topo da Internet (o “arquivo-raiz”) aos demais doze servidores.

A ICANN (tratada em detalhes abaixo) retém para si a tarefa de gerar o arquivo-raiz e repassá-lo ao servidor-autoridade. A tarefa de manutenção e gestão do servidor-autoridade foi (em meados da década de 1990, como se verá a seguir) delegada pelo Departamento de Comércio dos EUA à empresa Network Solutions Inc. (sucedida pela VeriSign, Inc.), sediada no estado da Virgínia nos EUA. Seu conteúdo - além de distribuído aos outros servidores-raiz - é também replicado em outros inúmeros servidores, tendo em vista dar celeridade de respostas aos bilhões de usuários que fazem consultas ao DNS (CANABARRO, 2014a).

De um ponto de vista operacional e conceitualmente estrito, a governança da Internet envolve a gestão dos recursos críticos que fazem com que a Internet funcione como um espaço global unificado e não fragmentado (KLEINWÄTCHER, 2015). Isso engloba, basicamente, a execução das chamadas "funções IANA"5, que podem ser resumidas nos seguintes termos: a gestão centralizada da raiz do DNS; a coordenação da alocação e distribuição dos recursos de endereçamento empregados para a identificação de equipamentos individuais e de redes completas (Sistemas Autônomos) que compõem a grande rede (números IP, nomes de domínio e Números de Sistemas Autônomos); e a manutenção da base de dados contendo os parâmetros dos protocolos a serem observados na implementação de tecnologias Internet. As funções IANA envolvem, de forma bastante simplificada, a manutenção e a administração de repositórios centrais de informação consultados e empregados pelas diferentes partes que compõem a rede global na organização dos fluxos de dados de uma ponta à outra, garantindo o funcionamento uniforme da Internet.

5 O acrônimo "IANA" se remete à Autoridade de Atribuição de Números da Internet, em inglês, isto é, Internet Assigned Numbers Authority (IANA). Essa autoridade pode ser resumida conforme as funções de gestão centralizada da raiz do DNS, a coordenação da alocação e distribuição dos recursos de endereçamento empregados para a identificação de equipamentos individuais e de redes completas (Sistemas Autônomos) que compõem a grande rede (números IP, nomes de domínio e Números de Sistemas Autônomos) e a manutenção da base de dados contendo os parâmetros dos protocolos a serem empregados para a integração à Internet. 
A governança da Internet pode ser percebida, porém, como algo que vai além da noção estreita, limitada à dimensão da coordenação e administração da raiz do DNS, definida por Wolfgang Kleinwächter (2015) como o microcosmo da Internet. Uma noção mais ampla, que envolve o tratamento de uma miríade de elementos no âmbito do complexo ecossistema da Internet - como questões relacionadas à privacidade, proteção de dados, regulamentação de telecomunicações, liberdade de expressão, responsabilização civil e criminal dos usuários, propriedade intelectual, acesso, entre outros - seria, por sua vez, o que o mesmo autor denomina de macrocosmo da governança da Internet.

Esse ecossistema complexo de governança da rede, seja ele na sua dimensão estreita ou ampla, é articulado por entidades técnicas e privadas que, sob diferentes jurisdições no planeta, possuem autoridade decorrente de suas responsabilidades sobre a arquitetura da Internet. Desenvolvimento de protocolos, padrões, alocações de endereços numéricos, operações de roteadores de pacotes de dados, entre outros, são atividades sob a responsabilidade de um ecossistema formado, sobretudo, por entidades técnicas e privadas.

A funcionalidade do DNS, ao longo do tempo, foi se modificando, em decorrência da privatização de sua gestão desde a década de 1990. Nomes domínios dotados de valor econômico, social, político e cultural passaram a conformar um mercado próprio, atraindo fluxos consideráveis de capital e habilitando uma nova arena de atuação para agentes financeiros. O simbolismo semântico desses identificadores tem gerado, constante e crescentemente, disputas acirradas em torno do seu uso.

O escopo da questão se ampliou entre 2012 e 2016, quando um programa de novos domínios de topo criado pela ICANN inseriu mais de mil novos nomes na raiz da Internet ${ }^{6}$, dentre eles, para citar alguns exemplos, nomes como.hotel,. boston,.volvo,.hbo. Alguns desses nomes foram alvos de contenciosos políticos, econômicos e culturais (alguns que se encontram, ainda hoje, sem solução): nomes referentes a regiões geográficas, como.amazon e.patagonia; capazes de identificar comunidades específicas, como.gay, e.doctor; e, ainda mais sensível, nomes atrelados a setores estruturantes da economia política internacional, como é o caso do.bank, do.insurance e do.army, entre outros. ${ }^{7}$ As implicações desse

6 A lista completa de nomes delegados até o fechamento desse texto encontra-se em ICANN (2018)

7 A ICANN abriu, até o presente momento, quatro (4) rodadas de inscrições de novos nomes domínios. Em 2000 foi "New TLD Application Process Overview" que inscreveram os nomes domínios: AERO, BIZ, COOP, INFO, MUSEUM, NAME e PRO (ICANN, 2000, s/p); em 2003 abriu-se a rodada para nomes domínios patrocinados 
fenômeno reverberam sobre o próprio papel da ICANN enquanto mantenedora e coordenadora da raiz da Internet, bem como espaço de articulação e definição das políticas que organizam esse novo mercado. É sobre esse assunto que tratam as seções subsequentes.

\section{A governança da internet na história geral do mundo}

As subseções a seguir apresentam, em perspectiva histórica, o desenvolvimento institucional da governança da Internet, conectando as três fases destacadas pelos autores ao contexto político mais amplo dentro do qual se desenvolveram. As linhas que dividem cada uma dessas fases são fluidas, mas giram em torno, sobretudo, do processo de criação da ICANN ao fim da década de 1990 e do escândalo precipitado pelas revelações feitas por Edward Snowden em 2013.

\section{A governança da Internet até o fim da década de 1990}

A Internet desenvolveu-se como um experimento, a ARPANET, financiado principalmente pelo Departamento de Defesa dos EUA, coordenado por pesquisadores estadunidenses em parceria com suas redes profissionais de diversas partes do mundo (ABBATE, 1999). A coordenação dos recursos que fazem dela uma rede única e garantem o funcionamento uniforme de todas as suas porções ao redor do planeta envolve a "execução das funções IANA". Tais funções foram desenvolvidas, desde a década de 1970 até o final da década de 1990, pelo núcleo duro de cientistas de universidades americanas envolvidas com o projeto central que deu origem à Internet global (MUELLER, 2002). A coordenação desses recursos ficou fora do alcance do conhecimento e do envolvimento público até recentemente

(Sponsored Top Level Domains), que consiste em nomes domínios que representam uma "comunidade" mais específica (ICANN, 2005, p. 1). Após a experiência de 2000 e 2003, abriu-se outro processo de inscrições de 2005 a 2007; e, por fim, em 2012, iniciou-se o quarto processo (que foi responsável pela explosão de nomes contidos na raiz do DNS). Todas essas iniciativas foram impulsionadas por agentes econômicos interessados em explorar o mercado que gira em torno dos identificadores alfanuméricos da Internet (historicamente concentrado nas mãos de algumas poucas entidades para além dos administradores de códigos de país). A quarta rodada da ICANN surgiu, porém, com barreiras de entrada altíssimas, sobretudo para o mundo em desenvolvimento: a mera candidatura a um nome pretendido custava, inicialmente, US \$ 285.000,00 (duzentos e oitenta e cinco mil dólares), isso sem considerar os valores inerentes a todo o processo de tramitação da candidatura. Disso resultou um panorama enormemente concentrado no Norte desenvolvido em detrimento do Sul global. Nesse sentido, ver Lacroix (2013). 
(DENARDIS, 2014), quando a Internet se popularizou e seu uso se tornou, efetiva e normativamente, ubíquo e inexorável nas sociedades contemporâneas.

Em virtude do início da comercialização do acesso à Internet nos Estados Unidos e à popularização da rede, todo o arcabouço complexo de supervisão das diferentes porções do projeto que gerou a Internet foi concentrado sob a supervisão do Departamento de Comércio do país. Durante o governo Clinton, a Internet foi percebida pelos formuladores da grande estratégia dos Estados Unidos, em preparação para a virada do século XX/XXI - sobretudo por Ira Magaziner, conselheiro sênior da administração Clinton em matéria de Desenvolvimento de Políticas na Casa Branca e supervisor das políticas de comercialização da Internet.

No 54 Encontro da ICANN, em Dublin, no ano de 2015, Magaziner faz referência àquele período:

[A] Internet oferecia a promessa de estimular a economia global de uma forma que nada fizera e, além disso, nós [do governo Clinton] também identificamos a sequência do genoma humano e o impacto que isso poderia ter na biotecnologia e, também, nas energias renováveis, como as três grandes áreas tecnológicas. Mas a Internet, nós sentíamos que estava vindo primeiro. E que se nós colocássemos em pé uma série de processos que a tornassem ‘amigável' com o mercado, para a Internet se desenvolver, para as pessoas investirem e um conjunto de acordos globais que a tornassem amigáveis, para a Internet decolar como meio comercial, nós sentimos que podíamos realmente ajudar a Internet a agitar a economia. (MAGAZINER, 2015, p. 5)

Em termos mais amplos, a década de 1990 foi o momento, segundo Silver e Arrighi (2012), da belle époque da hegemonia americana, o momento de bonança que antecede a crise que, no caso, foi a crise financeira do Leste Asiático, em 1997, reverberando inclusive na formação da bolha financeira que ficou conhecida como a "bolha '.com"” (TERABIT, 2014, p. 25). Esse momento do final do século XX consubstancia as consequências da expansão financeira percebida na década de 1970.

A preocupação de Ira Magaziner de "estimular a economia global", ao ser posta em perspectiva histórica, insere-se na própria reorganização do capitalismo (HARVEY, 2004), cujo regime de propriedade intelectual assume papel fundamental enquanto mecanismo de desapropriação privada de recursos sociais comuns preexistentes. É sobre esse fenômeno que se assenta a intensificação da comercialização do simbolismo semântico dos nomes domínios, que enseja o conflito, no âmbito da ICANN, sobre a "propriedade" desses recursos. Conflito 
que vai desaguar, mais recentemente, nas disputas entre corporações e Estados, sobre nomes domínios como.amazon,.guangzhou,.shenzen,.indians, entre outros ${ }^{8}$.

Assim, “as três grandes áreas de tecnologia”, referidas por Magaziner (2015) - genoma humano, energia renovável e Internet -, sinalizam, em certa medida, os novos campos mercantilizados pela reorganização do sistema-mundo capitalista. O momento, cabe sinalar, já é de ruptura com o "keynesianismo militar global do governo norte-americano” (ARRIGHI, 2009, p. 316) que estruturou o modelo de desenvolvimento do século XX pela produção e consumo em massa e consolidação de um neoliberalismo orientado pelas finanças.

A reorientação do capital às “três grandes áreas de tecnologia” nada mais é do que a busca do capital, mais uma vez na sua história, pela manutenção da sua “liberdade de escolha” (ARRIGHI, 2009, p. 5) para acumulação. A história do capitalismo, para Braudel (1983, p. 433), mostra que a característica essencial do capitalismo é a "flexibilidade ilimitada, sua capacidade de mudança e adaptação" . Em outras palavras, com a redução da expectativa do capital com sua própria liberdade de escolhas de acumulação no modelo de produção e consumo de massas do século XX, o capital buscou a expansão financeira até a oportunização de investimento em outro modelo de desenvolvimento que, a princípio, tem na Internet sua base material de organização.

Por isso, a orientação liberalizante das políticas de Ronald Reagan e Bill Clinton, bem documentada por Strange (1997), para Arrighi (2009, p. 309), não parece ser uma "tendência 'revolucionária”" do capital, mas, sim, a continuidade da tendência de longa duração que tem, dentre suas implicações, a “formação de blocos cada vez mais poderosos de organizações governamentais e empresariais como principais agentes da acumulação de capital em escala mundial". Foi justamente o que ocorreu em 1998, quando atribuiu-se a uma organização privada sem fins lucrativos - ICANN - o papel outrora relegado à comunidade de pesquisadores envolvida com a Internet.

Essa organização privada, sediada sob as leis do estado da Califórnia, orientada ao mercado, sem a preponderância de atores governamentais vis-à-vis

8 A disputa sobre esses nomes domínios, no âmbito dos trabalhos da ICANN, inicia em 2013, quando o Comitê Consultivo Governamental (GAC, em inglês) da ICANN recomenda à direção da organização a negação dos registros dos referidos nomes, solicitados pela Amazon Inc.; Guangzhou YU Wei Information Technology Co. Ver decisão em (ICANN, 2013a). O caso do.amazon assumiu notoriedade nos foros da ICANN pela extensão da resolução da disputa entre a corporação, amparada por congressistas estadunidenses, contra os interesses do governo brasileiro, ver em ICANN (2014a), e peruano, ver em ICANN (2014b).

9 Texto original: "its unlimited flexibility, its capacity for change and adaptation". 
atores não governamentais, por força de um contrato firmado com o governo estadunidense, passou a servir como o ponto focal para a governança do que viria a ser um recurso de interesse público global. Assim, além da responsabilidade de execução das funções IANA, a ICANN passou a servir de fórum de definição de políticas relacionadas aos recursos críticos para o funcionamento da Internet (CANABARRO; BORNE, 2015).

Na seção seguinte, será apresentada a evolução das disputas políticas internacionais em torno da ICANN. Essas disputas, relacionadas ao seu papel técnico de coordenação e execução das funções IANA, expressam a conformação de uma possível transformação nos mecanismos de governança global, própria da oportunidade de ascensão de uma nova hegemonia, do novo ciclo de acumulação sistêmico, no século XXI.

\section{A governança da Internet a partir da criação da ICANN}

A criação da ICANN integra a estratégia do governo estadunidense de atribuir aos agentes econômicos nacionais o protagonismo na governança global dos recursos críticos ao funcionamento da Internet (DIREITO, 2010; LUCERO, 2010; CANABARRO, 2014a). Inserida em um contexto de massificação do uso da Internet, a constituição da ICANN surge como alternativa de resolução ao acirramento de conflitos domésticos nos Estados Unidos sobre a autoridade dos recursos críticos da rede.

A resolução doméstica estadunidense, consequentemente, desconsiderou em grande medida os questionamentos de outros Estados acerca o monopólio norte-americano sobre a raiz da Internet. Como consequência, em virtude de sua proximidade, no tempo, com a realização da CMSI, entre 2003 e 2005, a questão da governança sobre a raiz da Internet passou a integrar a agenda mais abrangente relativa à Sociedade da Informação no âmbito da ONU. A síntese, em parte, das duas fases da Cúpula, foi o assentamento das bases para o desenvolvimento de um regime internacional em sua interface com a difusão das Tecnologias da Informação e da Comunicação. Como será descrito nessa seção, os Estados Unidos contaram com expressiva vantagem estrutural na definição da agenda da governança da Internet, decorrente do monopólio da autoridade sobre a raiz da Internet, bem como da localização dela sob sua jurisdição.

A CMSI de 2003 consistiu, basicamente, em uma arena para delimitação da abrangência de quais temas - a administração dos recursos centrais da rede; 
política pública vinculada ao acesso e liberdade de expressão; comércio eletrônico; segurança cibernética, entre outros - seriam, ou não, objeto de política internacional no que se convencionou delimitar como "Sociedade da Informação". O elemento que perpassava todos esses temas era o impasse sobre o modelo da organização internacional e, portanto, de autoridade responsável sobre tal conjunto de questões, sobretudo no que diz respeito à governança da Internet. Assim, o questionamento do papel da ICANN era a variável constante ao longo de toda cúpula, mesmo que a agenda da Cúpula não se limitasse à IANA (KLEINWÄTCHER, 2007).

Os Estados Unidos, com aliados europeus, advogaram pelo protagonismo do setor privado na formação do regime internacional em torno das questões relacionadas à Internet. Em contraponto, a China e o G-77 advogaram a formação de uma autoridade intergovernamental para tratar do assunto. A CMSI, em 2003, deliberou sobre a formação de um Grupo de Trabalho sobre Governança da Internet (GTGI). A função do GTGI era definir, em um relatório, (i) o escopo de temas da noção de "governança da Internet"; (ii) as questões relevantes para políticas públicas dentro dessa definição; e (iii) um entendimento comum sobre as diferentes responsabilidades dos diferentes setores (GTGI, 2005, p. 3).

O relatório, dentre outras questões, apresentou três modelos - sendo a ICANN a organização base de cada modelo - para orientar um concerto entre os países e demais setores na construção de uma organização internacional encarregada da gestão dos recursos alfanuméricos da rede e outras políticas públicas para Internet. Às vésperas do CMSI em Túnis, em 2005, o governo estadunidense emitiu, via sua Agência Nacional de Telecomunicações e Informação (NTIA, em inglês), uma nota de posicionamento, apontando que não abandonaria o seu papel de supervisão do funcionamento da ICANN como garantia da estabilidade e segurança do funcionamento da Internet (NTIA, 2005).

A fase de 2005, da Cúpula, acabou por reconhecer a não necessidade de envolvimento de governos nacionais com as questões técnicas e operacionais do dia a dia da gestão da Internet (Agenda de Túnis, parágrafo 69) (ITU, 2005, p. 10). Preponderou, portanto, a visão segundo a qual a coordenação dos recursos críticos deveria ocorrer sem a participação direta dos Estados. A posição unilateral dos Estados Unidas relativamente à IANA foi mantida sob a justificativa de que uma mudança poderia acarretar interrupções, instabilidades e até mesmo a fragmentação da Internet global.

A discussão sobre a autoridade na governança da Internet seria reinserida na agenda da política internacional na realização da Conferência Mundial sobre 
Telecomunicações Internacionais (CMTI), em 2012, em Dubai, para atualização das Regulamentações das Telecomunicações Internacionais (RTI) que possuíam mais de 25 anos de existência, portanto, e sequer faziam qualquer referência à Internet. O evento não foi distensionado, com o agravante de vazamento para o público de propostas - conhecidos como WCITLeaks para o público em geral, fora das salas de trabalho em Dubai, de atualizações das RTI controversas relacionadas ao recrudescimento de mecanismos de controle de conteúdo para fins de proteção de direitos de propriedade intelectual em detrimento do livre acesso ao conhecimento e para fins de garantia da segurança pública e da segurança internacional. E, ainda, ao favorecimento dado a modelos de negócio do setor das telecomunicações tradicionais (rádio, televisão, telefonia, etc.) em detrimento dos modelos de negócio que fizeram a Internet prosperar.

As RTI foram atualizadas sem fazer menção à governança da Internet. Entretanto, no plenário para votação das regulamentações, a delegação estadunidense declarou-se impedida de aprovar o texto, em reação à proposição da delegação iraniana em aprovar um anexo não vinculante que destacava a importância das UIT continuarem discutindo a governança da Internet. Ainda no plenário, Canadá, Polônia, Holanda, Dinamarca, Kenya, Nova Zelândia, Costa Rica e República Tcheca fizeram semelhante manifestação à americana. Ao fim e ao cabo, 89 países assinaram o texto e 55 países não assinaram (CANABARRO, 2014b; DOURADO, 2012).

Contudo, o que, definitivamente, disparou o processo conhecido como transição IANA, desvinculando a operação da ICANN do contrato de serviço com o Departamento de Comércio dos Estados Unidos, foram as revelações, pelo analista de sistemas da Agência Nacional de Segurança (NSA, em inglês) dos EUA, Edward Snowden, em 2013, a jornalistas do The Guardian e Washington Post ${ }^{10}$, dos mecanismos e infraestrutura de espionagem perpetrados pela NSA em aliança com, ao menos, outros quatro países - Reino Unido, Austrália, Nova Zelândia e Canadá. Brasil e Alemanha protagonizaram, a partir desse episódio, reação imediata aos escândalos no âmbito das Nações Unidas, solicitando ao Alto Comissariado das Nações Unidas dos Direitos Humanos que recomendasse princípios aos Estados membros sobre a "proteção do direito à privacidade em casos de vigilância das comunicações doméstica e extraterritorial” (NAÇÕES UNIDAS, 2013, p. 3), aprovados pelo Comissariado em novembro de 2014 (UNMULTIMEDIA, 2014).

10 Ver o The Guardian (2013) e Washington Post (2013). 


\subsection{O Escândalo Snowden e os prospectos de transformação da governança global da Internet}

A reação às espionagens estadunidenses, protagonizadas por Brasil e Alemanha, foi o movimento político internacional que convergiu o debate amplo sobre governança da Internet com o questionamento da autoridade unilateral dos EUA sobre as funções IANA. Após a presidenta da República Federativa do Brasil, Dilma Vana Rousseff, cancelar a visita de chefe de Estado agendada aos EUA, e, em seu discurso na $68^{\mathrm{a}}$ Assembleia Geral das Nações Unidas, repudiar a "rede global de espionagem eletrônica" (BRASIL, 2013a, s/p), propondo cinco princípios que deveriam orientar a constituição de um "marco civil multilateral", o Chefe-Executivo da ICANN, Fadi Chehadé, reuniu-se com Rousseff para transmitir a ela o reconhecimento do protagonsimo que o Brasil assumiu na definição de agenda da governança global da Internet, em nome das demais organizações técnicas. Nessa reunião, propôs, ainda, a realização do encontro que ficou conhecido como Encontro Multissetorial Global sobre o Futuro da Governança da Internet - NETmundial (BRASIL, 2013b).

A visita ocorreu logo após a emissão da "Declaração de Montevideo sobre o Futuro da Cooperação da Internet”, no dia 7 de outubro de 2013, por um conjunto de organizações técnicas, que integram o macrocosmo do ecossistema da Internet. Nessa declaração, os porta-vozes das referidas organizações "advertem contra a fragmentação da Internet no nível nacional” possível pela "fragilização da confiança e segurança (...) devido às recentes revelações de monitoramento e vigilância pervasiva". Em vista disso, conclamaram para a aceleração da "globalização da ICANN e das funções IANA" (ICANN, 2013).

O Encontro NETmundial ocorreu entre os dias 23 e 24 de abril de 2014, em São Paulo. Na agenda de trabalho, duas questões foram abordadas: a definição de princípios mundiais comuns para a condução da governança global da Internet e a criação de um roteiro para a evolução do ecossistema de governança da rede mundial. O documento (juridicamente não vinculante) resultante do evento contém provisões, entre outras coisas, relativas à democratização da governança da Internet pelo reconhecimento da natureza global da rede e da necessidade de desvinculação das funções IANA da supervisão unilateral dos Estados Unidos em prol da comunidade global.

Importante destacar que, dez dias antes do evento, o Departamento de Comércio dos Estados Unidos divulgou sua intenção de não renovar o vínculo 
contratual mantido com a ICANN, estabelecendo o prazo do vínculo vigente, o ano de 2015, que foi prorrogado para 2016; para transferir seu papel de supervisor à "comunidade multissetorial da governança da Internet” (NTIA, 2014). Os EUA impuseram quatro condições a serem cumpridas para a não renovação do contrato: (a) a manutenção da ICANN como uma organização multissetorial (ou seja, capaz de acomodar atores governamentais e não governamentais "em pé de igualdade" na definição de políticas para a governança da Internet); (b) a necessidade de preservação da segurança, estabilidade e funcionalidade do DNS; (c) o atendimento das expectativas dos usuários/clientes das funções IANA; e (d) a manutenção da Internet como uma rede aberta. O documento foi, ainda, taxativo ao dizer que a "NTIA não aceitará propostas que substituam o papel da NTIA por uma solução liderada por governos ou uma organização intergovernamental" (SIC) ${ }^{11}$ (NTIA, 2014). Em síntese, antecipando qualquer movimentação de outros atores para definir o futuro da governança da raiz da Internet, o governo estadunidense definiu, assim como nas prévias da CMSI em 2005, limites a serem estritamente observados para a reformatação da governança da Internet.

Pelas condições estadunidenses, as ICANN eram alçadas, de uma corporação privada, conforme apontado anteriormente, à condição de “organização internacional" capaz de servir como arena política para equacionar os interesses e coordenar a ação coletiva em torno da gestão dos recursos críticos da Internet global. Além disso, e principalmente, as já referidas condições proscreveram a possibilidade de transformação do regime centrado no setor privado em um regime constituído em torno de arranjos intergovernamentais. Com base nessas premissas, a própria chamada "comunidade da ICANN"12 desenvolveu, de 2014 a 2016, o plano de transição submetido ao Departamento de Comércio dos EUA para a avaliação do atendimento às condicionalidades; e, por fim, ao Congresso dos Estados Unidos, para aprovação ou rejeição da ação executiva da Presidência dos EUA, de descontinuar o vínculo contratual.

De 2014 a 2016, o plano de transição foi desenvolvido no âmbito das atividades da ICANN, em um processo questionável em termos de amplitude e diversidade de participação, com sobrepeso de representantes de empresas de tecnologia; escritórios de propriedade intelectual; e registrantes de nomes domínios dos

11 Versão original: "NTIA will not accept a proposal that replaces the NTIA role with a government-led or an intergovernmental organization solution”.

12 Cujo público dominante são representantes estadunidenses de empresas de tecnologias; escritórios de propriedade intelectual; e registrantes de nomes domínios. Ver em CIS (2015). 
Estados Unidos ${ }^{13}$. A previsão inicial de encerramento das atividades de confecção do plano para setembro de 2015 foi adiada por doze meses.

Em síntese, a possível transformação nos mecanismos de governança global encontra na conclusão da privatização das funções IANA a sua primeira experiência, com a consolidação da ICANN enquanto um regime internacional privado. Grande parte dos desafios referentes às interfaces e sobreposições entre os componentes públicos e privados desse novo regime reside no fato da ICANN buscar constituir, agora, uma espécie de assembleia política deliberativa. Esse processo só deverá ser efetivamente finalizado na virada de 2018 para 2019. Todavia, a corporação, pela sua sede, está submetida à jurisdição da Califórnia. Seu arcabouço legal é baseado à luz da legislação californiana.

Persiste, portanto, a problemática acerca da necessidade de subordinação de Estados soberanos à jurisdição interna dos Estados Unidos para poderem participar do arcabouço institucional resultante da transição. Independentemente de outras questões adicionais que formam o mosaico complexo de controvérsias inerentes à governança da Internet, a quantidade de informações trazidas até aqui é o suficiente para que se possa apontar as principais questões que se abrem a partir da transição IANA para o estudo da governança global em um sentido mais amplo na contemporaneidade.

\section{O significado da transição iana para o estudo da governança global}

A alteração no modelo de governabilidade pode não ser, necessariamente, um processo consciente de todas as forças envolvidas; apenas de parte delas. Seja pelo interesse em modificar o statu quo no nível sistêmico ou pela resistência a essa modificação, há determinados agentes que são capazes de identificar nitidamente as oportunidades históricas que se abrem para o alcance de um ou outro desses objetivos.

Por exemplo, no início dos trabalhos para o plano de transição, em junho de 2015, Chehadé salientou o caráter sem precedentes da arquitetura institucional da ICANN em um contexto de crescente tensão entre componentes internacionais e transnacionais de governabilidade:

13 Ver em CIS (2015). 
A experiência da ICANN é única, não há nada parecido no planeta. Digam-me qual outra organização privada possui 115 governos assessorando-a? Não existe. Nós temos um modelo institucional bastante único (...) A Internet é transnacional, ela não é internacional. Grande diferença. Coisas internacionais (sic) são resolvidas por nações, mas você sabe a qual país pertence um número IP? Você não sabe. A Internet é desenhada para ser transnacional, portanto ela desafia o modelo legal 'vestfaliano' que existe atualmente. Agora, queremos criar uma guerra entre o modelo internacional e o modelo transnacional? A resposta é 'não', porque você não ganharia essa guerra. Todo mundo perderia. O desafio que a ICANN oferece ao mundo - e é um lindo desafio - é de estabelecer um modelo onde as pessoas internacionais (sic) - vão e vejam o GAC trabalhar é notável - podem se encontrar com outras pessoas, que acreditam que os governos deveriam ser fechados (sic) - [riso] as vezes, esse é outro extremo, mas nós trabalhamos juntos e nós descobrimos como casar os dois poderes [o modelo internacional e o transnacional] e isso nós chamamos de modelo multissetorial. Difícil mas impressionante (CHEHADÉ, 2015, 01'02'32 - 01'04'”2, grifo dos autores) ${ }^{14}$.

O pronunciamento do ex-CEO da ICANN, Fadi Chehadé, sinaliza a consciência das transformações potenciais que podem decorrer da transição da IANA, inclusive a própria necessidade de se conciliar a articulação das noções de multilateralismo e multissetorialismo, não as tratando como categorias necessariamente estanques. Em suma, o que se pleiteia, inclusive para outros âmbitos além da governança dos números e nomes da rede, é a mudança nas noções de legitimidade e autoridade, bem como no ponto de equilíbrio dos centros decisórios que determinam o rumo da governança global.

A consolidação desse formato específico de autoridade privada - expresso como uma das concepções de multissetorialismo - depende, ao menos no âmbito da governança da Internet, da forma como a ICANN, enquanto “organização privada internacional”, será capaz de lidar com os dilemas que emergirem a partir

14 Versão transcrita no idioma original: "The ICANN experience is unique, there is nothing like it on the planet. Tell me which other private organization has 115 governments advising it? Does not exist. We have a very unique institutional model (...) The Internet is transnational, it is not international. Big difference. International things (sic) are solved by nations, but do you know to which country an IP number belongs? You do not. The Internet is designed to be transnational, so it defies the legal 'westiphaalian' model that exists today. Now, do we want to create a war between the international model and the transnational model? The answer is 'no' because you could not win this war. Everyone would lose The challenge that ICANN offers the world - and it is a beautiful challenge - is to establish a model where international people (sic) - go and see the GAC work is remarkable they can meet other people, who believe that Governments should be closed (sic) - [laughter] - this is another extreme, but we worked together and we figured out how to marry the two powers [the international and the transnational model] and this we call a multistakeholder model. Difficult but impressive" 
da sua agenda político-econômica e com o desafio de coordenar a ação coletiva em torno da Internet no plano global. O acompanhamento dessa discussão, nos marcos das relações internacionais, já sinaliza uma possível continuidade reflexiva acerca do tema no que tange à dinâmica capital-Estado na atualidade. Dessa dinâmica, ramifica-se outra orientação reflexiva sobre a própria agenda políticoeconômica relacionada ao Programa de Novos Nomes Domínios Genéricos ${ }^{15}$ da ICANN, que tem movimentado um mercado de, aproximadamente, 4 bilhões de dólares anuais ${ }^{16}$. Com seus contornos programáticos delimitados inteiramente dentro do regime privado da ICANN, com esmagador protagonismo de atores econômicos dos Estados Unidos, a geração de novas estruturas e novas dinâmicas capazes de influenciar a economia internacional impõe o acompanhamento sistemático de suas relações com outros setores da economia, como as finanças internacionais.

Retornemos ao pronunciamento de Ira Magaziner (2015) sobre a constituição da ICANN pelo governo estadunidense. Ele manifesta, nesse pronunciamento, a consciência de alguns agentes políticos e econômicos sobre as dimensões das transformações do momento vivido em meados da década de 1990. Ademais, demonstra a consciência das implicações dessas transformações para oportunizar o reposicionamento da hegemonia no sistema-mundo diante do prelúdio da decadência do “século americano” (SILVER; ARRIGHI, 2012, p. 78).

A materialidade da oportunidade dessas transformações foi demonstrada justamente no fim da bonança da década de 1990, no centro hegemônico. A crise financeira do final dessa década representa, segundo a análise de longa duração do capitalismo, o anúncio da “crise terminal da hegemonia mundial” (SILVER; ARRIGHI, 2012, p. 80). O ano de 2008, nesse sentido, marcado por uma crise que reverberou por todo o planeta (SILVER; ARRIGHI, 2012; MANYIKA et. al, 2016), seria, quiçá, a manifestação da "crise terminal”, momento análogo, para Silver e Arrighi (2012, p. 82), da financeirização do ciclo estadunidense à financeirização do ciclo genovês, em 1560; ao ciclo holandês, em 1740; e ao ciclo britânico, de 1873. A retomada da expansão material da produção e do comércio ocorre, se a tendência de longa duração se mantiver, quando uma adaptação da composição Estado-capital estabelecer as condições de direcionamento da expansão financeira para expansão material.

15 Para um histórico sobre o Programa de Novos Nomes Domínios Genéricos da ICANN, ver em ICANN (2018). 16 Relatório da CIRA Internet Factbooks 2016. Ver em CIRA (2016). 
Há que se repisar que o processo de adaptação do capital, para cada período histórico, envolve momentos identificados por Arrighi (2009) como momentos de transição entre os ciclos sistêmicos de acumulação do capitalismo. A transição costuma ser caracterizada por um contexto de aparente caos sistêmico, decorrente das situações de crise - sinalizando o limite de determinado modelo de desenvolvimento do capitalismo em sustentar suas próprias contradições - que tem como consequência o acirramento da disputa entre os Estados e entre os agentes econômicos pela construção de outra ordem hegemônica sobre o sistema-mundo. Nesse contexto, a noção de hegemonia gramsciana transposta para as relações internacionais, segundo Robert Cox (2002), considera a capacidade das classes dominantes em projetarem, doméstica e internacionalmente, suas noções de ordem mundial. A construção da dominação depende, justamente, da configuração da adaptação do capital frente aos limites do ciclo de acumulação anterior, demandando uma reorganização da base material e da base de ideias do novo ciclo a ser constituído. Para legitimá-lo, os agentes político-econômicos formam mecanismos de governabilidade política para legitimar a divisão internacional do trabalho.

Esse conjunto de coisas permite analisar o fato do EUA terem postergado a privatização plena da execução das funções IANA por, aproximadamente, 13 anos - desde a realização do CMSI em 2003 até a conclusão do processo em 2016. Em suma, essa postergação, no cenário de transição de um ciclo para outro, representa um momento, um possível interregno de não hegemonia, em que a antiga hegemonia está em derrocada e a nova ainda não se conformou (COX, 1981). Isso não quer dizer que esse interregno tenha cessado, com a conclusão da privatização. Em certa medida, é nesses termos que a discussão do próprio Congresso dos Estados Unidos, no dia 30 de setembro de 2016, reflete a percepção do contexto de transição. No momento crucial de autorizar, ou não, o Poder Executivo em avançar com a transição, senadores estadunidenses justificavam sua oposição ao plano de transição pelo receio da perda do prestígio e poder no cenário internacional, algo que poderia "fortalecer o papel de regimes autoritários na governança da Internet” (US SENATE, 2016). Em termos gramscianos, como já é sabido, o Estado nas relações internacionais é palco das disputas domésticas por blocos de agentes e instrumento de projeção da noção de ordem mundial do bloco dominante (COX, 1981) ${ }^{17}$.

17 Já em 2018, a persistência dos republicanos do país em reverter a transição IANA voltou à pauta política. Nesse sentido, ver em Político (2018). 
Para a emergente hegemonia se consolidar, seja ela qual for, sua forma de autoridade deve ser legitimada, entre outras coisas, por meio de mecanismos de governabilidade. É sobre essa dimensão da disputa hegemônica que se deve analisar a arquitetura institucional e a prática multissetorial da ICANN.

Calcadas em noções normativas imprecisas de multissetorialismo (KOVACS, 2013; MALCOLM, 2015) a arquitetura institucional e a prática da ICANN carregam, em determinados grupos econômicos e políticos, uma conotação de antagonismo à noção do multilateralismo estruturante das relações internacionais no século XX (multilateralismo, entendido equivocadamente como sinônimo absoluto de intergovernamentalismo). Aliás, multilateralismo e multissetorialismo têm sido tratados como antônimos não apenas na ICANN, mas no campo da governança da Internet como um todo (MUELLER, 2010; MUELLER, 2017).

$\mathrm{O}$ antagonismo decorre de uma narrativa que trata processos governamentais e intergovernamentais como intrinsecamente morosos e não necessariamente democráticos; e processos multissetoriais, como a materialização da "governança sem governo", eficientemente desenvolvida pelo setor privado e pelo terceiro setor, propalados como horizonte normativo da governança político-social no receituário neoliberal que é próprio da virada do século XX para o XXI. Assim, o multilateralismo, institucionalizado no arranjo intergovernamental da Organização das Nações Unidas durante o século XX, seria produto da criação e do desenvolvimento de mecanismos de governabilidade do ciclo sistêmico passado, o “modelo legal 'vestfaliano'” referido por Chehadé (2015), formado a partir de rupturas e continuidades de ciclos anteriores do capitalismo. A ICANN, desde sua criação até o presente momento, conteria, então, papel embrionário similar para o emergente ciclo de acumulação do século XXI e seu amadurecimento institucional de natureza multissetorial antagonizaria com o mecanismo passado, o intergovernamentalismo.

Como já tivemos oportunidade de dizer em outro lugar, porém, nos debates relativos ao tema da governança em geral, é bastante comum que se desconsiderem as diferenças ontológicas entre multilateralismo e multissetorialismo, como se verá na seção final desse texto. Isso decorre da confusão entre, por um lado, o processo de governança em si (o processo de orientação e delimitação dos rumos e objetivos a serem perseguidos por determinado arranjo social); e, por outro, as diversas modalidades de agentes a quem se pode atribuir a responsabilidade pela consecução daqueles objetivos (dentre eles - mas não apenas -, o Estado e suas estruturas executivas no âmbito doméstico, bem como organizações 
intergovernamentais no âmbito internacional, assim como arranjos de composição variável contendo atores estatais e não estatais) (CANABARRO, 2014a).

\section{Conclusões}

Tomando emprestadas as palavras de Beverly Silver e Giovanni Arrighi (2012, p. 78), "[c]omo podemos dar sentido a esta frenética alteração de percepções sobre a era da história do mundo em que estamos entrando?". A resposta pode ser por meio da comparação do presente com períodos passados; o que significa que, para o entendimento acerca das implicações da transição IANA, não podemos desvinculá-las do contexto que em estão inseridas: o momento de reorganização do sistema-mundo capitalista. Conforme delimitado no escopo deste trabalho, focamos a análise, dentre o conjunto de fenômenos evolutivos, recorrentes e anômalos tratados nos trabalhos de Silver e Arrighi (2012), dos mecanismos de legitimação que se relacionam com a constituição de autoridades sobre a governabilidade do sistema de Estados. A transição da IANA toca diretamente nesse assunto, sobretudo pela implicação política potencial de revisão do sistema multilateral em preferência de um sistema multissetorial (entendido como sucedâneo ao intergovernamentalismo como expressão do primeiro) .

A crise financeira de 2008, assim como suas análogas de ciclos sistêmicos passados, é outro momento, agravante, de queda da expectativa do capital com sua própria liberdade de acumulação, como Braudel (1983) havia considerado no passado. A realização de novos programas de inscrições de novos nomes domínios, especialmente a quarta rodada, de 2012, indica a escolha de parte do capital em investimentos para acumulação. Com a alocação de investimentos sobre esses recursos, os domínios, advém também a revisão dos mecanismos de governabilidade que, no caso, encontra-se no embate entre multilateralismo, tratado enquanto sinônimo de processo governamental e intergovernamental, e multissetorialismo, enquanto "governança sem governo".

Por isso, é preciso que se diga que multilateralismo não é necessariamente um sinônimo de intergovernamentalismo. A despeito do tratamento de multilateralismo como sinônimo de intergovernamentalismo ser prática corrente nas relações internacionais e na diplomacia, é preciso que se diga que multilateralismo e intergovernamentalismo operam em planos ontológicos distintos. O primeiro refere-se a uma noção abstrata da natureza da participação na vida política 
internacional (com um nível decrescente de pluralidade quando se consideram a noção de multilateralismo, bilateralismo e unilateralismo). O segundo, a uma noção operacional relacionada à natureza dos agentes capazes de participar da vida política internacional institucionalizada. É possível, nesse sentido, que arranjos multilaterais e bilaterais sejam operacionalizados pela via do intergovernamentalismo. Esses mesmos arranjos podem ser operacionalizados multissetorialmente (quando estão aptos a participar do processo atores outros que não apenas representantes governamentais ${ }^{18}$ - e.g.: como no caso da Organização Internacional do Trabalho, de certas comissões do Conselho Econômico e Social da ONU e de inúmeras reuniões de cúpula e fóruns internacionais, como no caso da própria CMSI). Para colocar cada coisa em seu devido lugar, práticas intergovernamentais são conceitualmente unissetoriais; assim como arranjos bilaterais e multilaterais, e até mesmo unilaterais, podem eventualmente envolver - em seus processos - maior ou menor participação multissetorial.

O tratamento de multilateralismo e multissetorialismo como intrinsecamente inconciliáveis, sendo o multilateralismo como indesejável para a governança da Internet, pode ser considerado como uma forma narrativa datada: a narrativa construída para justificar, a partir da década de 1980, a contenção da ação do Estado em arranjos públicos de governança, dentro dos quais se pretende atribuir maior relevância a agentes do setor privado na definição e execução de políticas públicas. O multissetorialismo, por envolver uma pluralidade mais vasta de atores sociais em arranjos horizontalizados, seria - nesse caso - o parâmetro de boa governança contemporânea para a substituição da governança, necessariamente apresentada como menos participativa e transparente, centrada na figura do aparato estatal em um sentido weberiano. Isso opera em desconsideração à realidade complexa em que, entre os dois extremos que geralmente dividem o debate público a respeito da Internet, há um ponto intermediário possível que envolve multilateralismo e multissetorialismo como passíveis de coexistência, oferecendo uma alternativa de democratização da política internacional por meio da abertura à participação nos processos de formulação e tomada de decisão. $\mathrm{O}$ avanço da investigação a respeito desse equilíbrio é uma das principais avenidas que se abrem para o estudo das relações internacionais em uma era digital.

18 Denardis e Raymond (2013) explicam que são variáveis a serem consideradas, no estudo do multissetorialismo, a "natureza dos atores" envolvidos e as "relações de poder", mais ou menos verticalizadas, existentes entre eles. 


\section{Referências}

ABBATE, J. Inventing the Internet. Cambridge, Massachusetts: MIT Press, 1999.

ARRIGHI, Giovanni. O longo século XX: dinheiro, poder e as origens do nosso tempo. Rio de Janeiro: Contraponto, 2009;

BRASIL. "Brasil vai sediar encontro mundial sobre governança da Internet em 2014". Portal Brasil. 09 outubro 2013b. Disponível em: < http://www.brasil.gov.br/ governo/2013/10/brasil-vai-sediar-encontro-mundial-sobre-governanca-da-Internetem-2014 > . Acesso em: 18 jun 2017;

BRASIL. "Discurso da Presidenta da República, Dilma Rousseff, na abertura do Debate Geral da $68^{\circ}$ Assembleia-Geral das Nações Unidas - Nova Iorque/EUA”. 2013a. Página Inicial > Discursos > Discursos da Presidenta. Disponível em: < http://www2. planalto.gov.br/acompanhe-o-planalto/discursos/discursos-da-presidenta/discursoda-presidenta-da-republica-dilma-rousseff-na-abertura-do-debate-geral-da-68aassembleia-geral-das-nacoes-unidas-nova-iorque-eua > . Acessado em: 26 abril 2018. BRAUDEL, Fernand. A dinâmica do capitalismo. Editora Rocco. Rio de Janeiro; 1987. . The Wheels of Commerce. Civilization and Capitalism 15th-18th Century. Volume II. 1983. Book Club Association London.

CANABARRO, Diego R. O longo 2014 da governança da Internet - um balanço do $9^{\circ}$ IGF. poliTICS, $\mathrm{n}^{\circ}$ 19. Dezembro/2014b. Instituto Nupef. Rio de Janeiro.

CANABARRO, Diego R., BORNE, Thiago. Internet Governance in a Post-Snowden Brazil. 56th ISA Annual Conference. February 18th-21st, 2015 - New Orleans, USA.

CANABARRO, Diego Rafael. Governança Global da Internet: tecnologia, poder e desenvolvimento. Volume 1 e 2. UFRGS. Porto Alegre. 2014a.

CHEHADÉ, Fadi. Newcomer Welcome Section. ICANN53 - Buenos Aires. 21 de Junho de 2015. Liberator C. Buenos Aires. Disponível em: < https://icann.adobeconnect.com/p820ep 382gc/?launcher $=$ false\&fcsContent $=$ true\&pbMode $=$ normal $>$. Acesso em: 27 Set. 2016; COX, Robert W. Social Forces, States and World Orders: Beyond International Relations Theory. Millenium: Journal of International Relations. Vol 10. 204-254.1981.

. Gramsci, Hegemony and International Relations : An Essay in Method. Millennium: Journal of International Studies. Vol 12. Issue 2. pp. 49-66. 2002.

CIRA. The Domain Name Industry. Cira Internet Factbook 2016. Disponível em: < https://cira.ca/factbook/domain-industry-data-and-canadian-Internet-trends/ domain-name-industry > . Acesso em: 20mar 2018.

CIS. The 'Global Multistakholder Community' is Neither Global Nor Multistakeholder. 20 de outubro de 2015. Disponível em: < https://cis-india.org/Internet-governance/ blog/global-multistakeholder-community-neither-global-nor-multistakeholder $>$. Acesso: 20 mar. 2018. 
DENARDIS, L. The Global War for Internet Governance. Yale University Press, 2014.

DENARDIS, L.; RAYMOND, M. Thinking Clearly About Multistakeholder Internet Governance. Artigo apresentado no 8th Annual GigaNet Symposium, em 21 de outubro de 2013, Bali, Indonésia. Disponível em: < http://ssrn.com/abstract = 2354377> . Acesso em: 21 dez 2013.

DIREITO, Denise do Carmo. Governança da internet: Construção da Agenda Brasileira Negociada em uma Realidade de Múltiplos Atores. Instituto de Ciência Política. UnB. Brasília. 2010.

DOURADO, Eli. Behind closed doors at the UN's attempted "takeover the Internet". Arstechnica. Laaw \& Disorder. 12/20/2012. Disponível em: < https://arstechnica. com/tech-policy/2012/12/behind-closed-doors-at-the-uns-attempted-takeover-ofthe-Internet/2/ > . Acesso em: 11 jun 2017.

GTGI. Report of the Working Group on Internet Governance. Châteu de Bossey. Junho de 2005. Disponível em: < http://www.wgig.org/docs/WGIGREPORT.doc > Acesso em: 23 maio 2017.

HARVEY, David. El nuevo imperialismo. Edição Akal. Madrid, Espanha. 2004. Disponível em: < http://libgen.io/get_new.php?md5 = BAE7C0707681ABD0C6CC877FAB2C1D78 > . Acesso em: 01 out. 2015.

ICANN. Report on TLD Applications: Background. 09 November 2000. Disponível em: < https://archive.icann.org/en/tlds/report/report-i-09nov00.htm > Acesso em: 19 mar 2018.

. Durban GAC Communiqué. 18 de julho de 2013a. Disponível em: < https://gacweb. icann.org/display/GACADV/2013-07-18-Obj-Amazon > . Acesso em: 19 mar 2018. . Montevideo Statement on the Future on Internet Cooperation. Announcements. 07 Oct 2013b. Disponível em: < https://www.icann.org/news/announcement-201310-07-en > . Acesso em: 18 jun 2017;

. Correspondence. 11 abril 2014a. Disponível em: < https://www.icann.org/en/ system/files/correspondence/filho-almeida-to-crocker-14apr14-en.pdf > . Acesso em: 20 mar. 2018;

. Correspondence. 11 abril 2014b. Disponível em: < https://www.icann.org/en/ system/files/correspondence/filho-almeida-to-crocker-14apr14-en.pdf $>$. Acesso em: 20 mar. 2018;

. Status Report on the sTLD Evaluation Process. 03 December 2005. Disponível em: < https://archive.icann.org/en/tlds/stld-apps-19mar04/stld-status-report.pdf > . Acesso em: 19 mar 2018

. Delegated Settings. 2018. Disponível em: < https://newgtlds.icann.org/en/programstatus/delegated-strings > . Acesso em: 20/03/2018. 
IETF. RFC 1591/1994. 1994. Disponível em: < https://www.ietf.org/rfc/rfc1591.txt > . Acesso em: 20 mar. 2018.

ITU. Tunis Agenda for the Information Society. WSIS-05/TUNIS/DOC/6(Rev. 1)-E. 18 November 2005. Tunis. Disponível em: < http://www.itu.int/net/wsis/docs2/ tunis/off/6rev1.html > . Acesso em: 18 jun 2017.

KLEINWÄTCHER, Wolfgang. Internet Governance Outlook 2015: Two Processes, Many Venues, Four Baskets. Circle ID. Blog. 03 de Janeiro de 2015, 10:25. Disponível em: < http://www.circleid.com/posts/20150103_Internet_governance_outlook_2015_2_ processes_many_venues_4_baskets/ > . Acesso 26 nov. 2017.

. The History of Internet Governance. In: OSCE. Governing the Internet: Freedom and Regulation in the OSCE Region Vienna, Austria, OSCE, 2007, pp. 41- 64. Disponível em: < http://www.osce.org/fom/26169 > . Acesso em: 17 dez 2017.

KLENSIN, J. Role of the Domain Name System (DNS). RFC 3467. Informational. February 2003. Disponível em: < https://docs.google.com/document/d/15HDhoUwMFlXeItQ4_eViw4aITgtrdcWHr24VqBhpnM/edit > . Acesso em: 12 jun 2017;

KOVACS, Anja. A third way? Proposal for a decentralised, multistakeholder global Internet governance model. Internet democracy project. 2013. At < https://Internetdemocracy. in/reports/a-third-way-proposal-for-a-decentralised-democratic-Internet-governanceinvolving-all-stakeholders/ > . Acesso September 27, 2016.

LACROIX, D. Governance of Top Level Domains (TLDs): a failed revolution? Anais da 1st International Conference on Internet Science, Brussels, April 9-11, pages 133-141, 2013. LUCERO, Everton Frask. Governança da Internet: Aspectos da Formação de um Regime Global. Instituto Rio Branco. Washington, DC. 2010. Disponível em: < http://funag. gov.br/loja/download/822-Governanca_da_Internet.pdf > . Acesso: Março 24, 2014. MAGAZINER, Ira. DUBLIN - Transition Perspectives: From an Internet Pioneer and the US Congress. ICANN54. Dublin, Ireland. October 18, 2015. Disponível em: < https://meetings.icann.org/en/dublin54/schedule/sun-transition-perspectives/ transcript-transition-perspectives-18oct15-en.pdf > . Acesso em: 20 jun 2017.

MALCOLM, Jeremy. Criteria of meaningful stakeholder inclusion in Internet governance. Internet Policy Review - Journal on Internet regulation. Vol. 4, Issue 4. December 162015. MANYIKA, James; LUND, Susan; BUGHIN, Jacques; WOETZEL, Jonathan; STAMENOV, Kalin; DHINGRA, Dhruv. Digital Globalization: The New Era of Global Flows. McKinsey \& Company, 2016.

MUELLER, M. Networks and States: The Global Politics of Internet Governance. Londres, MIT Press, 2010.

. Ruling the Root: Internet Governance and the Taming of Cyberspace. Cambridge, USA, MIT Press, 2002.

. Will the Internet Fragment? Sovereignty, Globalization, and Cyberspace. Cambridge, UK: Polity, 2017. 
NAÇÕES UNIDAS. The right for privacy on the digital age. General Assembly. 1 November 2013. A/C.3/68/L.45. Disponível em: < http://www.un.org/ga/search/view_doc.asp? symbol = A/C.3/68/L.45 > . Acesso em: 12 jun 2017 .

NIC.br. Documentos da Cúpula Mundial sobre a Sociedade da Informação: Genebra 2003 e Túnis 2005. São Paulo: Comitê Gestor da Internet no Brasil, 2014.

NTIA. NTIA Annouces Intent to Transition Key Internet Domains Name Functions. March 14, 2014. Dosponível em: < https://www.ntia.doc.gov/press-release/2014/ntia-announcesintent-transition-key-Internet-domain-name-functions > . Acesso em: 20 jun 2017. . US's Principles on the Internet's Domain Name and Addressing System. June 30, 2005. Disponível em: < https://www.ntia.doc.gov/other-publication/2005/usprinciples-Internets-domain-name-and-addressing-system > . Acesso em: 24 maio 2017. POLÍTICO. Redl's internet transition pledge. 24 de janeiro de 2018. Disponível em: < https://www.politico.com/newsletters/morning-tech/2018/01/24/redls-internettransition-pledge-082204 > . Acesso em: 20 mar. 2018.

SILVER, Beverly; ARRIGHI, Giovanni. O fim do longo século XX. In: VIEIRA, Pedro A. (org. Et al.). O Brasil e o Capitalismo Histórico: Passado e Presente na Análise dos Sistemas-Mundo. São Paulo, SP: Editora Cultura Acadêmica. 2012. pp. 77-96

STRANGE, Susan. The Retreat of the Sate: The diffusion of power in the world. Cambrigde Studies in International Relations. 1997.

TERABIT.Submarine Telecoms Industry Report. Issue 3. 2014. Submarine Telecoms Forum. Disponível em: < http://www.terabitconsulting.com/downloads/2014-submarinecable-market- industry-report.pdf > . Acesso em: 15 set. 2015;

THE GUARDIAN. NSA whistleblower Edward Snowden: 'I don't want to live in a society that does these sort of things'. Video. 09 de junho de 2013. Disponível em: < https://www. theguardian.com/world/video/2013/jun/09/nsa-whistleblower-edward-snowdeninterview-video > . Acesso: 20 mar. 2018.

WASHINGTON POST. Edward Snowden comes forward as source of NSA leaks. 09 junho 2013. Disponível em: < https://www.washingtonpost.com/politics/intelligence-leaderspush-back-on-leakers-media/2013/06/09/fff80160-d122-11e2-a73e-826d299ff459_ story.html?utm_term $=.9 f 1855083501>$. Acesso: 20 mar. 2018.

UNMULTIMEDIA. Nações Unidas adotam resolução sobre privacidade na era digital. Notícia e Midia Rádio ONU. 25/11/2014. Disponível em: < http://www.unmultimedia. org/radio/portuguese/2014/11/nacoes-unidas-adotam-resolucao-sobre-privacidadena-era-digital/\#.WT6lQje1vQo > . Acesso em: 12 jun 2017.

US SENATE. Senate and House Chairs Call for Administration to Reconsider ICANN Internet Transition, September 8, 2016. Press Release. Disponível em: < https://www.commerce.senate.gov/public/index.cfm/pressreleases?ID = E4B18487419C-45D5-ACF1-2E41743801C2 > . Acesso em: 16 Dez. 2016. 